\title{
Photoluminescence and damage recovery studies in Fe-implanted ZnO single crystals
}

\author{
T. Monteiro, ${ }^{\text {a) }}$ C. Boemare, and M. J. Soares \\ Departamento de Física, Universidade de Aveiro, 3800-193 Aveiro, Portugal \\ E. Rita and E. Alves \\ Instituto Tecnológico e Nuclear, 2686-953 Sacavém, Portugal
}

(Received 24 October 2002; accepted 18 March 2003)

\begin{abstract}
We report $\mathrm{Fe}^{3+}$-related emission in ion-implanted $\mathrm{ZnO}$ single crystals. Iron ions were implanted at room temperature with $100 \mathrm{keV}$ and a fluence of $1 \times 10^{16} \mathrm{Fe}^{+} / \mathrm{cm}^{2}$, and were submitted to annealing treatments in vacuum and in air. After implantation, the damage raises the minimum yield $\left(\chi_{\min }\right)$ from $2 \%$ to $50 \%$. Annealing in an oxidizing atmosphere leads to a reduction of the implantation damage, which is fully recovered after annealing at $1050{ }^{\circ} \mathrm{C}$ with a $\chi_{\min } \sim 3 \%$ in the implanted region. With extrinsic excitation, red Fe-related emission is observed at low temperatures. The intensity is dependent on the annealing conditions. For samples annealed in air, the luminescence can be detected up to $120 \mathrm{~K}$. When a comparison is made between unimplanted and post-implanted annealed samples, noticeable changes on near-band-edge and deep-level photoluminescence spectra are observed. A thermally populated structured green emission could be observed in the sample annealed in air, as shown by the temperature-dependent photoluminescence excitation studies. (C) 2003 American Institute of Physics. [DOI: 10.1063/1.1573341]
\end{abstract}

\section{INTRODUCTION}

$\mathrm{ZnO}$ is a wide-band-gap material $\left(E_{g} \sim 3.37 \mathrm{eV}\right.$ at room temperature) with an exciton binding energy of $60 \mathrm{meV}^{1}$ that has potential technological applications in both shortwavelength light-emitting devices and semiconductor spin electronics. ${ }^{2-4}$ Undoped, as-grown $\mathrm{ZnO}$ presents nominal $n$-type conductivity, while $p$-type doping is difficult to obtain. This is the major drawback for fabrication of suitable optoelectronic devices. However, recent theoretical calculations, ${ }^{5}$ Hall-effect and conductivity measurements on molecular-beam-epitaxy-grown homoepitaxial $\mathrm{ZnO}$ thin films doped with $\mathrm{N}$ (see Ref. 6) may indicate that $p$-type $\mathrm{ZnO}$ can be achieved, opening the way for the production of high-quality $\mathrm{ZnO}$-based devices. Besides the in-grown doping process, ion implantation is a well-established technique that allows for the introduction of dopants in crystal lattices in a controlled way. For instance, successful optical activation and lattice recovery have been achieved by ion implantation in $\mathrm{GaN}^{7}$

Typically, with intrinsic excitation, the low-temperature photoluminescence (PL) spectra of undoped $\mathrm{ZnO}$ single crystals are characterized by complex near-band-edge (NBE) spectra dominated by the recombination of free excitons (FXA), rotor states $(E>3.37 \mathrm{eV})$, and neutral donor/ acceptor bound-exciton complexes $\left(\mathrm{D}^{0} \mathrm{X}, \mathrm{A}^{0} \mathrm{X}\right)$ near $3.36 \mathrm{eV}$ followed by $72.8-\mathrm{meV}$ LO phonon replicas. ${ }^{1,8,9}$ At lower energies, $29.9 \mathrm{meV}$ below the exciton complexes, two-electron satellite (TES) recombination is observed. ${ }^{1,8,9}$ Donoracceptor pair (DAP) recombination at $3.22 \mathrm{eV}$ followed by LO phonon replicas is usually present. ${ }^{1,8,9}$ Besides these structured NBE emissions, deep-level structureless emissions

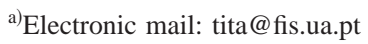

are commonly observed in undoped $\mathrm{ZnO}$ single crystals, ${ }^{10,11}$ powder samples, ${ }^{12,13}$ thin films, ${ }^{14,15}$ and nanocrystalline particles. ${ }^{16}$ The centers responsible for the unstructured emission bands in the green, yellow, and red spectral regions are usually assumed to be due to different native defects in $\mathrm{ZnO}$, such as oxygen vacancy $\left(\mathrm{V}_{\mathrm{O}}\right)$, zinc vacancy $\left(\mathrm{V}_{\mathrm{Zn}}\right)$, interstitial zinc, interstitial oxygen, and antisite defect $\left(\mathrm{O}_{\mathrm{Zn}}\right) \cdot{ }^{10-16}$ Until now, no consensus has existed in the literature concerning the nature of the defects where luminescence originates. In addition, theoretical studies propose controversial explanations to the green emission in $\mathrm{ZnO}$ due to transitions involving $\mathrm{V}_{\mathrm{Zn}}{ }^{17}$ and $\mathrm{V}_{\mathrm{O}}{ }^{18}$

Besides the intrinsic nature of the defects responsible for the green and yellow/red emission bands, some authors argue that the recombination processes are due to extrinsic impurities, such as $\mathrm{Cu}$ and $\mathrm{Li}$, respectively. ${ }^{19-26}$ The Cu-related emission band has been known to be a LO-phonon-assisted transition with zero phonon lines $(\alpha, \beta, \gamma)$ near $2.86 \mathrm{eV}$ and with maximum at $\sim 2.43 \mathrm{eV}^{19-24}$ This emission is also characterized by a fast exponential decay $\left(\sim 440 \mathrm{~ns}\right.$ at $\left.1.6 \mathrm{~K}^{19}\right)$ and presents a nearly structured mirror-image PL excitation (PLE) spectrum at low temperatures with its excitation maximum near $3.12 \mathrm{eV}^{20-22}$ The recombination model for this structured $\mathrm{Cu}$-related emission corresponds to a transition of an acceptor-type bound exciton $\left[\mathrm{Cu}^{+}\left(d^{9}+\mathrm{e}\right), \mathrm{h}\right]$ to the ground state $\left({ }^{2} \mathrm{~T}_{2}\right)$ of $\mathrm{Cu}^{2+}\left(d^{9}\right)$ ion. ${ }^{21-23}$ This state acts as an electron-trapping level located $\sim 200 \mathrm{meV}$ below the bottom of the conduction band. ${ }^{21,23}$ The quantum yield of the green $\mathrm{PL}$ in $\mathrm{ZnO}$ is known to be of near $100 \% .^{23}$ Thus, it is concluded that the $\left(\mathrm{Cu}^{+}, \mathrm{h}\right)$ state in crystals with less than 250 ppm copper concentration decays purely radiatively to the ground state. ${ }^{23}$ 
Recently, the vibronic-assisted green band was explained as an overlap of phonon DAP-assisted transitions between two shallow donors, with $E_{\mathrm{D} 1}=30 \mathrm{meV}$ and $E_{\mathrm{D} 2}=60 \mathrm{meV}$ and a deep unknown acceptor. ${ }^{27}$ These donor activation energies are common in $\mathrm{ZnO}$ samples, $E_{\mathrm{D} 1}$ being recently related with hydrogen. ${ }^{28}$ Annealing treatments in air in $\mathrm{ZnO}$ single crystals are known to induce changes in the green emission band. ${ }^{24}$ While in unannealed samples, a broad, unstructured band peaked at $2.47 \mathrm{eV}$ is observed, after annealing, the structured $\mathrm{Cu}$-related band with maximum at 2.43 $\mathrm{eV}$ is detected. ${ }^{24}$ It has been suggested ${ }^{24}$ that the structureless emission is a DAP recombination involving $\mathrm{Cu}^{+}$acceptors.

In the present work, we report on the optical and structural studies in high-quality $\mathrm{ZnO}$ single crystals implanted with iron ions and submitted to post-implantation annealing in air and vacuum ambient. Two main issues are addressed within the work: the changes in the NBE and green emission transitions observed after annealing, and the intraionic $\mathrm{Fe}^{3+}$ emission. In order to obtain further insight on the recombination processes involved on the green emission observed after annealing, we have performed temperature-dependent PLE spectroscopy on the band maximum between $25 \mathrm{~K}$ and RT. The PLE spectra reveal that the population of the green emission is a thermally activated process involving impurity or defect levels inside the band gap. In both the implanted and annealed samples, $\mathrm{Fe}^{3+}$-related emission is observed, with an intensity that is dependent on the annealing conditions. In samples annealed in air, $\mathrm{Fe}^{3+}$ luminescence is observed up to $120 \mathrm{~K}$, revealing that, as in $\mathrm{GaN}$, ion implantation provides a useful tool to incorporate magnetic ions in a $\mathrm{ZnO}$ host.

\section{EXPERIMENTAL DETAILS}

High-quality $\mathrm{ZnO}$ single crystals ( $\mathrm{Zn}$-face) grown by seeded chemical vapor transport from Eagle-Picher Technologies, LLC, were implanted at RT with a fluence of 1 $\times 10^{16} \mathrm{~cm}^{-2}$ of $\mathrm{Fe}$ ions with $100 \mathrm{keV}$. The samples were subjected to a four-step annealing process $\left(30 \mathrm{~min}\right.$ at $300^{\circ} \mathrm{C}$ $+30 \mathrm{~min}$ at $600^{\circ} \mathrm{C}+30 \mathrm{~min}$ at $900^{\circ} \mathrm{C}+30 \mathrm{~min}$ at $1050^{\circ} \mathrm{C}$ ) both in air and in vacuum. Crystalline quality and damage recovery were studied by Rutherford backscattering spectrometry and channeling (RBS/C). The measurements were performed using a 1-mm collimated $2-\mathrm{MeV}^{4} \mathrm{He}^{+}$beam with the samples mounted in a computer-controlled two-axis goniometer with an accuracy of $0.01^{\circ}$. The backscattered particles were detected by two surface barrier silicon detectors placed at $160^{\circ}$ and close to $180^{\circ}$ with respect to the beam direction, and with energy resolutions of 13 and $16 \mathrm{keV}$, respectively. Particle-induced x-ray emission (PIXE) was measured with a $10-\mathrm{mm}^{2} \mathrm{Si}(\mathrm{Li})$ detector of $150-\mathrm{keV}$ resolution and a $5-\mu \mathrm{m}$ Be window.

PL measurements were carried out with a $325-\mathrm{nm} \mathrm{cw}$ $\mathrm{He}-\mathrm{Cd}$ laser with an excitation power density typically less than $0.6 \mathrm{~W} \mathrm{~cm}^{-2}$, and with a Xe lamp coupled to a monochromator. PLE spectroscopy was provided by a Xe lamp dispersed by a monochromator. Time-resolved spectra (TRS) were carried out with a pulsed Xe lamp as an excitation source and a boxcar system for detection (setup resolution

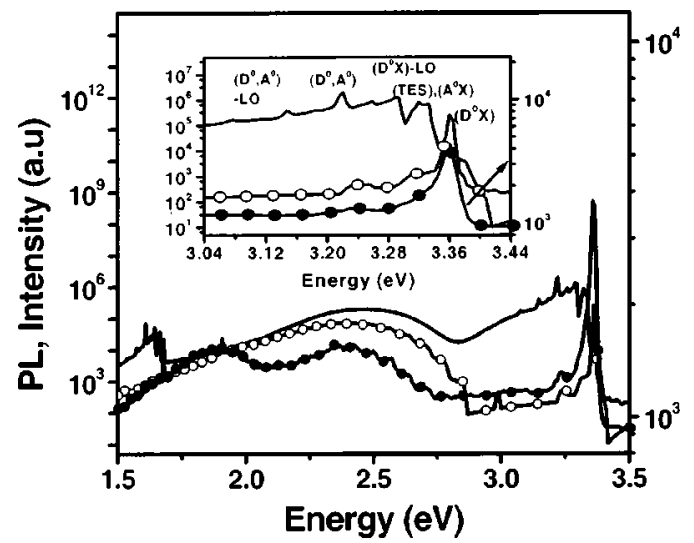

FIG. 1. Steady-state PL spectra observed at $14 \mathrm{~K}$ with $\mathrm{He}-\mathrm{Cd}$ excitation for unimplanted sample (full line), and iron-implanted samples annealed in vacuum (full line with closed circles) and in air (full line with open circles). Inset: enlarged spectra of NBE spectral range.

from hundreds of $\mu$ s to seconds). The PL was measured between $14 \mathrm{~K}$ and RT using a closed-cycle helium cryostat and collected in a $90^{\circ}$ geometry. In both cases, the luminescence was dispersed by a Spex 1704 monochromator $(1 \mathrm{~m}, 1200$ $\mathrm{mm}^{-1}$ ) and detected by a cooled Hamamatsu R928 photomultiplier. The presented spectra are all corrected to spectral responses.

\section{RESULTS AND DISCUSSION}

Figure 1 shows a comparison between the PL spectra obtained with above-band-gap excitation ( $\mathrm{He}-\mathrm{Cd}$ excitation source) at $14 \mathrm{~K}$ for the unimplanted and iron-implanted zinc oxide samples (Zn-face).

With intrinsic He-Cd excitation, noticeable changes are observed in the spectra of unimplanted and post-implanted annealed samples. In the NBE spectral region (inset of Fig. 1), the 14-K PL spectra of the undoped sample are dominated by lines at 3.36, 3.333, 3.319, 3.293, 3.258, 3.22, 3.147, and $3.076 \mathrm{eV}$. Similar emission lines were previously reported. ${ }^{1,8,9}$ The transitions are currently assigned to $\mathrm{D}^{0} \mathrm{X}$ (and $\mathrm{A}^{0} \mathrm{X}$ ) complexes, TES, and DAP recombinations. ${ }^{1,8,9}$ After implantation and annealing procedures, the NBE PL is mainly dominated by the $3.36 \mathrm{eV}$ emission, with minor lines at 3.309 and $3.239 \mathrm{eV}$ also observed for the sample annealed in air.

As presented in Fig. 1, deep emission bands are clearly observed in all samples. In accordance with previous results ${ }^{24}$ in the unimplanted sample, only a green "bell shaped" unstructured band peaked at $\sim 2.47 \mathrm{eV}$ is observed, whereas after implantation and annealing treatments, a structured green band peaked with a maximum at $\sim 2.43 \mathrm{eV}$ is observed. Its characteristics are similar to the previously reported $\mathrm{Cu}$-related ${ }^{19-24}$ emission. With our time-resolved spectroscopy setup, the emission could not be detected. This indicates, as previously reported, ${ }^{19}$ a transition with a fast lifetime (shorter than hundreds of $\mu \mathrm{s}$ ). Besides the green PL, a structureless red band with maximum near $1.9 \mathrm{eV}$ is also detected. At $25 \mathrm{~K}$ and under low-excitation conditions (Xe lamp +monochromator), an unstructured emission peaked near $2.43 \mathrm{eV}$ can be observed in implanted and anncaled 


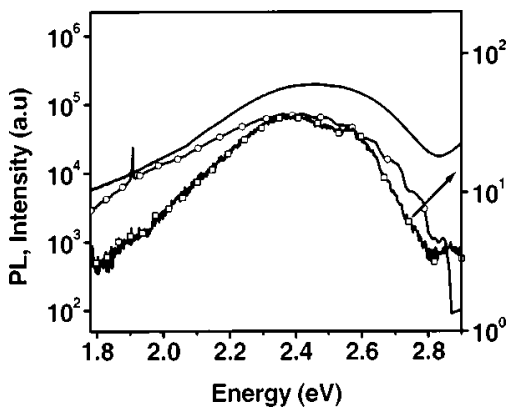

FIG. 2. Steady-state PL spectra observed at $14 \mathrm{~K}$ with $\mathrm{He}-\mathrm{Cd}$ excitation for unimplanted sample (full line) and iron-implanted sample annealed in air (full line with open circles). Full line with open squares corresponds to the 25-K PL of the same iron-implanted sample observed with band-gap excitation obtained with a Xe lamp coupled to a monochromator.

samples in the same spectral region in which the structured emission occurs. These observations are consistent with previous reports ${ }^{20}$ that indicate the absence of structure for T $\sim 20 \mathrm{~K}$. In Fig. 2, the comparison between the steady-state spectra for sample annealed in air is presented.

In order to obtain further insight on the recombination processes involved in the green band observed after annealing, temperature-dependent PLE spectroscopy has been carried out on the band maximum using a Xe lamp coupled to a monochromator. In Fig. 3, the temperature-dependent PLE and PL spectra (observed with excitation on the PLE maximum) are presented for selected temperatures between $25 \mathrm{~K}$ and RT.

While the band maximum of the green PL band remains constant with increasing temperature, the same is not observed for the temperature-dependent PLE spectra. At $25 \mathrm{~K}$, the PLE spectra show that the green PL band could be excited for energies higher than $\sim 3.05 \mathrm{eV}$ (onset of PLE spectra) with increasing excitation efficiency with light in resonance with neutral donor/acceptor complexes. This means that at low temperatures, free carriers or localized carriers on shallow impurities are needed to effectively excite the green band. With increasing temperature, these shallow impurities became thermally ionized and new extrinsic population channels are in the origin of the green PL recombination. It is clear that for temperatures above $40 \mathrm{~K}$, the PLE band is well below the band gap, and for higher temperatures, the band enlarges and there is an energy shift to lower energies larger than the band-gap dependence of $\mathrm{ZnO}$ (inset of Fig. 3). Likely candidates for this indirect extrinsic population of the green emission are, for instance, thermally ionized DAP recombination centers with species that indirectly populate the green recombination band. This justifies the absence of the peak shift of the green PL emission with increasing temperature. When the excitation is made on the band maximum of PLE spectrum, the integrated PL intensity of the green emission follows the same PLE behavior, increasing with increasing temperature until $100 \mathrm{~K}$, followed by a decrease for higher temperatures. The temperature dependence of the PL integrated intensity [inset of Fig. 3(b)] can be fitted according to
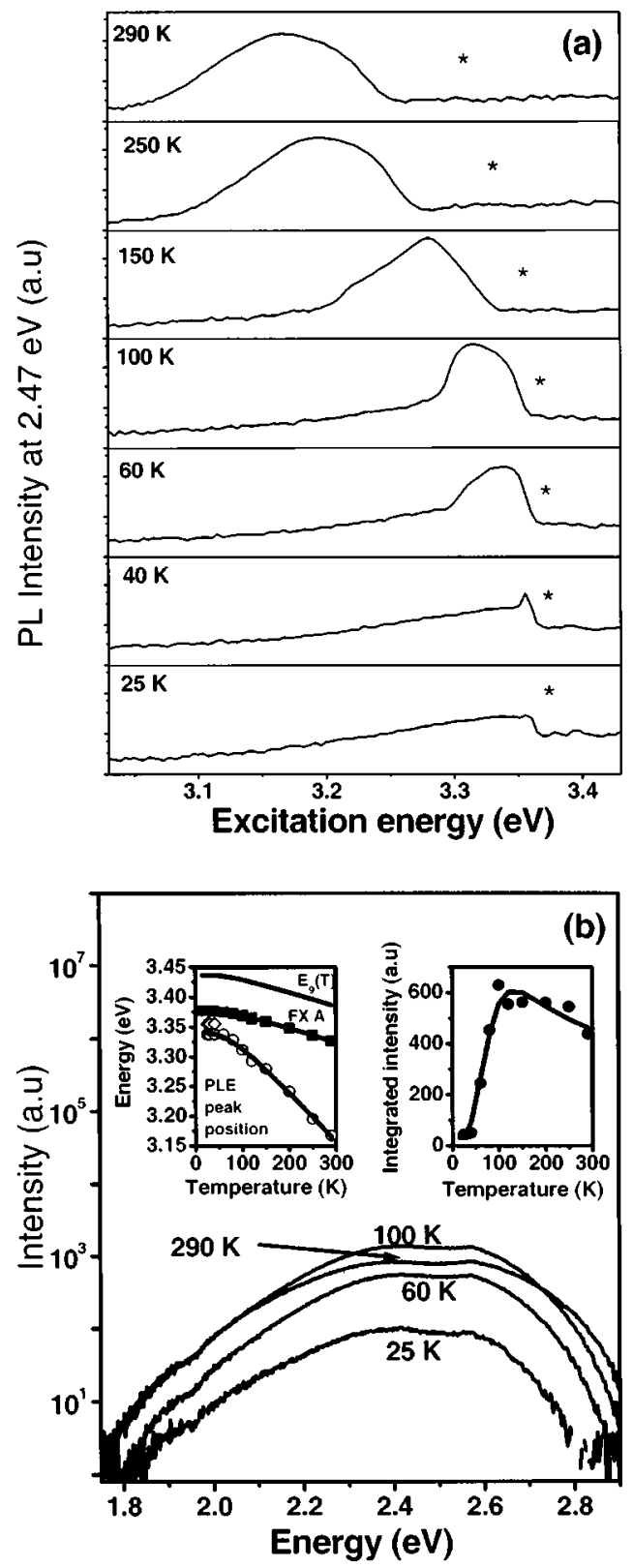

FIG. 3. (a) Temperature-dependent PLE spectra performed on the $2.47-\mathrm{eV}$ band maxima (the asterisks correspond to the temperature dependence of FXA described in Ref. 1). (b) Temperature dependence of green PL spectra observed with excitation on the band PLE maxima. Insets: temperature dependence of integrated intensity of green band, peak position of FXA, and band-gap dependence with temperature. Also enclosed is the behavior of the peak position of the PLE spectra with temperature.

$$
\begin{aligned}
I(T)= & I(0)+\left[C_{1} \exp \left(-E_{1} / k_{B} T\right) /\right. \\
& \left.\left(C_{2} \exp \left(-E_{2} / k_{B} T\right)+1\right)\right],
\end{aligned}
$$

where $E_{1,2}$ are the activation energies and $C_{1,2}$ are temperature-independent constants. The best fit to the intensity dependence of the green band was obtained for $E_{1}$ $=11.9 \pm 2.1 \mathrm{meV}, E_{2}=32.9 \pm 4.7 \mathrm{meV}$ with pre-exponential factors of $C_{1}=28.3 \pm 5.4$ and $C_{2}=9.6 \pm 1.4$.

The binding energy of an exciton bounded to a neutral donor measured from the energy difference between the FXA and $\mathrm{D}^{0} \mathrm{X}$ PL peak positions is $11.3 \mathrm{meV} .{ }^{1}$ This value matches the activation energy found for the thermal population of the 
observed green PL between 25 and $100 \mathrm{~K}$. This result suggests that the thermal release of excitons bound to neutral donors occurs within this temperature range. The ionization energy of the donor is estimated as $E_{\mathrm{D}}=59.5 \pm 2.1 \mathrm{meV}$, applying the Haynes rule (despite the fact that, so far, no evidence exists that the Haynes rule could be applicable to $\mathrm{ZnO}$ ), which agrees with the recently reported ${ }^{27-29} E_{\mathrm{D} 2}$ value of one of the donors present in $\mathrm{ZnO}$. As the PLE intensity increases with temperature, the thermal release of the exciton provides more carriers that could be trapped by the defect that feeds the levels where the green band originates. After $100 \mathrm{~K}$, the integrated PL intensity decreases with an activation energy near $32.9 \mathrm{meV}$, which could be due to competitive nonradiative processes of the populating defect or to intrinsic de-excitation of the $\mathrm{Cu}$-related center.

Besides the discussed green emission detected in our iron-implanted and annealed samples, red $\mathrm{Fe}^{3+}$-related luminescence is observed in both annealed samples, its relative intensity being higher in the sample annealed in air. This emission was previously observed in in-grown doped single crystals ${ }^{30}$ and in iron-contaminated $\mathrm{ZnO}$ sintered pellets. ${ }^{31} \mathrm{In}$ Fig. 4, the 14-K PL spectra observed with different excitation energies between 3.18 and $2.69 \mathrm{eV}$ are presented.

As for the green emission, and as pointed by the authors of Refs. 30 and 31, the Fe-related center is excited inside the band gap via an indirect process. It was previously reported ${ }^{30}$ that the low-temperature lifetime of the ${ }^{4} \mathrm{~T}_{1} \rightarrow{ }^{6} \mathrm{~A}_{1}$ transition of $\mathrm{Fe}^{3+}$ in $\mathrm{ZnO}$ corresponds to a single decay time of 25.2 ms. The time-resolved PL spectra performed with opened slits with 3.02-eV excitation presented in Fig. 4(b), clearly indicate the slow character of the observed transition. However, as previously observed in sintered pellets samples, ${ }^{31}$ the measured decay time in the band maximum at $14 \mathrm{~K}$ clearly shows that the red emission cannot be described by a single exponential decay (inset of Fig. 4). Its behavior is adjustable to bi-exponential fast and slow decays of 1.4 and $23 \mathrm{~ms}$, respectively.

In the iron-implanted sample annealed in air, the Ferelated emission can be detected up to $120 \mathrm{~K}$, as indicated in Fig. 5. At $14 \mathrm{~K}$, three main emission lines are observed at $1.7899,1.7885$, and $1.7872 \mathrm{eV}$. The band presents a similar vibronic coupling to the one observed previously. ${ }^{30,31}$ The dependence of the integrated Fe-related emission with temperature is shown by the Arrhenius plot in inset (a) of Fig. 5 . The thermal dependence of the integrated intensity can be fitted according to

$$
I(T) / I(0)=\left[1+C_{3} \exp \left(-E_{3} / k_{\mathrm{B}} T\right)\right]^{-1},
$$

where $E_{3}$ is the activation energy for the de-excitation processes and $C_{3}$ is a temperature-independent constant. The best fit was obtained for $E_{3}=8.45 \pm 0.51 \mathrm{meV}$, with a preexponential factor of $C_{3}=3.05 \pm 0.27$. A similar value was found in the sintered pellet samples. ${ }^{31}$

Structural studies on the samples were performed using RBS and PIXE analysis. The annealing recovery during the annealing in air is displayed in Fig. 6. The arrows inserted in the figure indicate the position of the surface edge for the different elements. As can be seen, Zn masks the Fe signal, making impossible the study of this element with RBS.
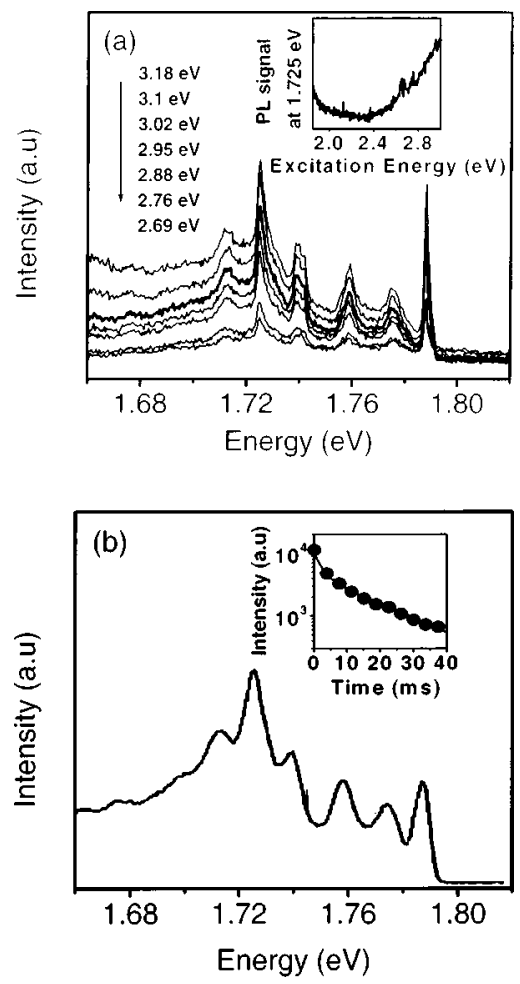

FIG. 4. (a) Steady-state PL spectra observed at $14 \mathrm{~K}$ for iron-implanted sample annealed in air with different excitation energies: 3.18, 3.1, 3.02, 2.95, 2.88, 2.76, and $2.69 \mathrm{eV}$. Inset: PLE spectra monitored at the PL band maximum. (b) 14-K TRS obtained with 3.02-eV excitation between 0.1 and $10 \mathrm{~ms}$ after the pulse lamp. Inset: measured decay time on the band maximum at $14 \mathrm{~K}$.

However, the implantation damage peak is well-pronounced in the [0001]-aligned spectra, leading to a minimum yield (ratio between the aligned and random spectra in the damage region) of $\chi_{\min } \sim 50 \%$. Defect recovery starts at a temperature as low as $300^{\circ} \mathrm{C}$, as indicated by the decrease to $43 \%$ observed in the minimum yield. After annealing at $1050{ }^{\circ} \mathrm{C}$, the recovery of the implantation damage is almost complete and the minimum yield reaches a value of $\chi_{\min } \sim 3 \%$ close to the one found before the implantation $\left(\chi_{\min } \sim 2 \%\right)$. The recovery during the annealing in vacuum follows the same

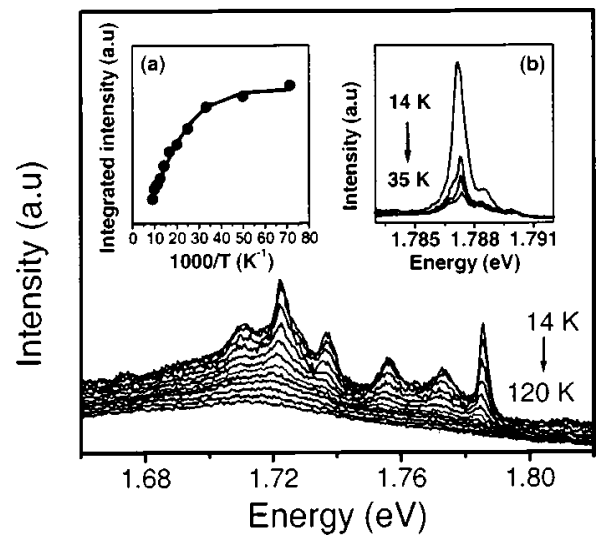

FIG. 5. Temperature dependence of steady state PL spectra observed with $410 \mathrm{~nm}$ excitation for iron-implanted sample annealed in air. Insets: (a) integrated intensity of PL as a function of temperature; (b) temperature dependence of the observed zero-phonon lines. 


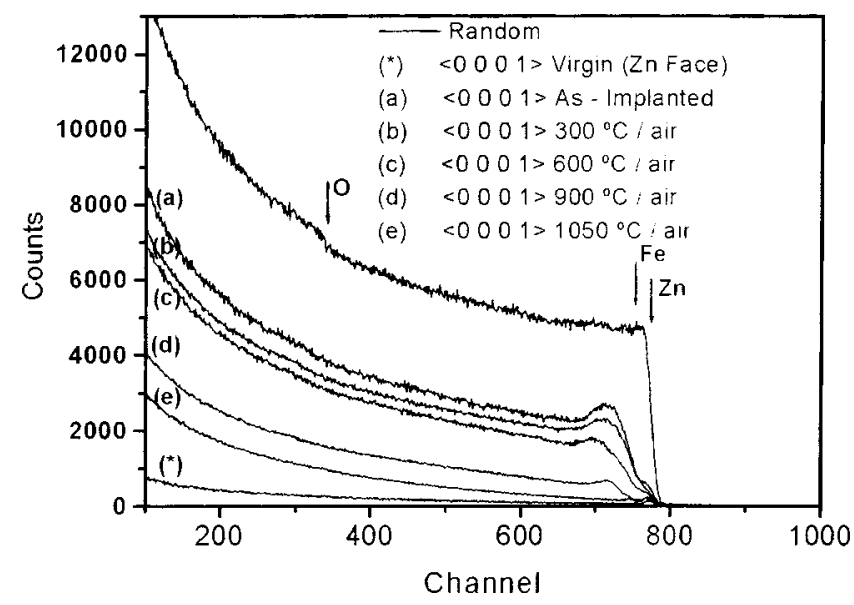

FIG. 6. Random and [0001]-aligned RBS spectra of a $\mathrm{ZnO}$ single crystal implanted with a fluence of $1 \times 10^{16} \mathrm{Fe}^{+} / \mathrm{cm}^{2}$ : before (a) and after annealing in air at (b) $300{ }^{\circ} \mathrm{C}$, (c) $600{ }^{\circ} \mathrm{C}$, (d) $900{ }^{\circ} \mathrm{C}$, and (e) $1050{ }^{\circ} \mathrm{C}$.

trend, but the residual damage is slightly higher after each annealing stage compared to the sample annealed in air. The minimum yield achieved after the annealing at $1050{ }^{\circ} \mathrm{C}$ in vacuum was, $\chi_{\min } \sim 6 \%$. The higher damage level found for the sample annealed in vacuum suggests the importance of free oxygen to reconstruct the damage region. The difference on the final amount of residual damage can also account for the different behavior observed in the optical properties of the two samples.

To obtain information on the iron behavior, we used the Fe x-ray emission induced by the ion beam. Figure 7 shows the random and [0001]-aligned PIXE spectra of the $\mathrm{ZnO}$ sample after implantation. The $\mathrm{K}_{\alpha}(8.63 \mathrm{keV})$ and $\mathrm{K}_{\beta}(9.57 \mathrm{keV})$ peaks of $\mathrm{Zn}$, as well as the $\mathrm{Fe} \mathrm{K}_{\alpha}$ line $(6.40$ $\mathrm{keV}$ ), are the main peaks observed in the spectra. The Fe $\mathrm{K}_{\alpha}$ clearly indicates the presence of the implanted $\mathrm{Fe}$ atoms in the sample. However, a PIXE spectra (not shown) obtained with a broad $(5-\mathrm{mm}) \mathrm{H}^{+}$beam and high statistic indicates that, besides $\mathrm{Fe}, \mathrm{Ni}$ and $\mathrm{Cr}$ are the main impurities in the studied samples, while $\mathrm{Cu}$ is undetectable with the setup used. $\mathrm{Ni}$ is known to give rise to PL emission in the infrared spectral region ${ }^{32}$ and is not the subject of the present study. Compared to its random yield the $\mathrm{Zn} \mathrm{K}_{\alpha}$ counts in [0001]alignment decrease to about $52 \%$ after implantation, while $\mathrm{Fe} \mathrm{K}_{\alpha}$ minimum yield is $73 \%$. According to the estimation

$$
f_{\text {sub }}=\left\{\left[1-\chi_{\min }(\mathrm{Fe})\right] /\left[1-\chi_{\min }(\mathrm{Zn})\right]\right\},
$$

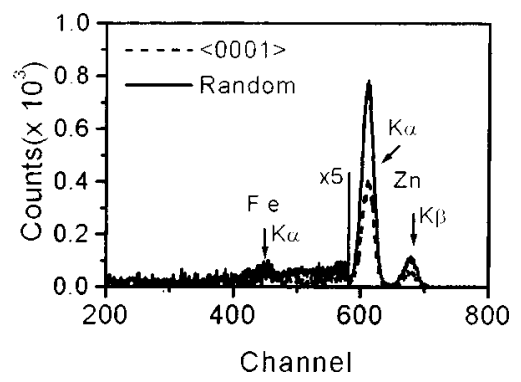

FIG. 7. PIXE spectra for the $\mathrm{ZnO}$ sample implanted with 1 $\times 10^{16} \mathrm{Fe}^{+} / \mathrm{cm}^{2}$. where $f_{\text {sub }}$ is the fraction of impurity in substitutional sites along the [0001] direction and $\chi_{\min }(\mathrm{Fe})$ and $\chi_{\min }(\mathrm{Zn})$ are the minimum yields of $\mathrm{Fe}$ and $\mathrm{Zn}$, respectively, we found $56 \%$ substitutionality after implantation. After the annealing at $1050^{\circ} \mathrm{C}$ in air, we measured an increase on the substitutionality of Fe along the $c$-axis to $73 \%$. The incorporation of a fraction of $\mathrm{Fe}$ in $\mathrm{Zn}$ sites is not unexpected, taking into account chemical considerations.

\section{CONCLUSIONS}

We have incorporated $\mathrm{Fe}$ into optically active sites $\mathrm{ZnO}$ single crystals by ion implantation. The iron-related emission was observed in the implanted samples being its intensity greater in samples submitted to annealing in air procedures.

Besides the red-related Fe luminescence, we have shown that the green PL in samples annealed in air is indirectly populated. The thermal dependence of the population of the levels where the green band originates is consistent with the ionization of species that give rise to shallow levels in the band gap as the donor located $60 \mathrm{meV}$ below the conduction band.

\section{ACKNOWLEDGMENTS}

The authors would like to thank to Professor E. Pereira for her interest in this work.

${ }^{1}$ C. Boemare, T. Monteiro, M. J. Soares, J. G. Guilherme, and E. Alves, Physica B 308-310, 985 (2001).

${ }^{2}$ K. Sato and H. Katayama-Yoshida, Semicond. Sci. Technol. 17, 376 (2002).

${ }^{3}$ K. Sato and H. Katayama-Yoshida, Jpn. J. Appl. Phys., Part 2 40, L334 (2001).

${ }^{4}$ K. Ueda, H. Tabata, and T. Kawai, Appl. Phys. Lett. 79, 988 (2001).

${ }^{5}$ C. H. Park, S. B. Zhang, and S.-H. Wei, Phys. Rev. B 66, 73202 (2002).

${ }^{6}$ D. C. Look, D. C. Reynolds, C. W. Litton, R. L. Jones, D. B. Eason, and G. Cantwell, Appl. Phys. Lett. 81, 1830 (2002).

${ }^{7}$ E. Alves, K. Lorentz, R. Vianden, C. Boemare, M. J. Soares, and T. Monteiro, Mod. Phys. Lett. B 28-29, 1281 (2001).

${ }^{8}$ R. E. Sherriff, D. C. Reynolds, D. C. Look, B. Jogai, J. E. Hoelscher, T. C. Collins, G. Cantwell, and W. C. Harsch, J. Appl. Phys. 88, 3454 (2000).

${ }^{9}$ K. Thonke, Th. Gruber, N. Teofilov, R. Schonfelder, A. Waag, and R. Sauer, Physica B 308-310, 945 (2001).

${ }^{10}$ S. Takata, T. Minami, H. Nanto, and T. Kawamura, Phys. Status Solidi A 65, K83 (1981).

${ }^{11}$ F. Leiter, H. Zhou, F. Henecker, A. Hofstaetter, D. M. Hoffmann, and B. K. Meyer, Physica B 308-310, 908 (2001).

${ }^{12}$ K. Vanheusden, W. L. Warren, C. H. Seager, D. R. Tallant, J. A. Voigt, and B. E. Gnade, J. Appl. Phys. 79, 7983 (1996).

${ }^{13}$ C. Gaspar, F. Costa, and T. Monteiro, J. Mater. Sci.: Mater. Electron. 12, 269 (2001).

${ }^{14}$ B. Lin, Z. Fu, Y. Jia, and G. Liao, J. Electrochem. Soc. 148, G110 (2001).

${ }^{15}$ S. A. Studenikin, N. Golego, and M. Cocivera, J. Appl. Phys. 84, 2287 (1998).

${ }^{16}$ A. van Dijken, E. A. Meulenkamp, D. Vanmaekelbergh, and A. Meijerink, J. Lumin. 90, 123 (2000).

${ }^{17}$ A. F. Kohan, G. Ceder, D. Morgan, and C. G. Van de Walle, Phys. Rev. B 61, 15019 (2000).

${ }^{18}$ S. B. Zhang, S. H. Wei, and A. Zunger, Phys. Rev. B 63, 75205 (2001).

${ }^{19}$ R. Dingle, Phys. Rev. Lett. 23, 579 (1969).

${ }^{20}$ I. Broser and R. K. F. Germer, Solid-State Electron. 21, 1597 (1978).

${ }^{21}$ D. J. Robbins, J. Lumin. 24/25, 137 (1981).

${ }^{22}$ P. J. Dean, D. J. Robbins, S. G. Bishop, J. A. Savage, and P. Porteous, J. Phys. C 14, 2847 (1981).

${ }^{23}$ P. Dahan, V. Fleurov, P. Thurian, R. Heitz, A. Hoffmann, and I. Broser, J. Phys.: Condens. Matter 10, 2007 (1998). 
${ }^{24}$ N. Y. Garces, L. Wang, L. Bai, N. C. Giles, L. E. Halliburton, and G. Cantwell, Appl. Phys. Lett. 81, 622 (2002).

${ }^{25}$ O. F. Scirmer and D. Zwingel, Solid State Commun. 8, 1559 (1970).

${ }^{26}$ D. Zwingel, J. Lumin. 5, 358 (1972).

${ }^{27}$ D. C. Reynolds, D. C. Look, and B. Jogai, J. Appl. Phys. 89, 6189 (2001).

${ }^{28}$ D. M. Hofmann, A. Hofstaetter, F. Leiter, H. Zhou, F. Henecker, B. Meyer, S. B. Orlinskii, J. Schmidt, and P. G. Baranov, Phys. Rev. Lett. 88, 45504 (2002).
${ }^{29}$ D. C. Reynolds, D. C. Look, B. Jogai, C. W. Litton, T. C. Collins, W. Harsch, and G. Cantwell, Phys. Rev. B 57, 12151 (1998).

${ }^{30}$ R. Heitz, A. Hoffmann, and I. Broser, Phys. Rev. B 45, 8977 (1992).

${ }^{31}$ C. Gaspar, L. Pereira, F. M. Costa, T. Monteiro, J. Han, A. M. R. Senos, and P. Mantas, 2000 International Semiconducting and Insulating Materials Conference, SIMC-XI, edited C. Jagadish and N. J. Welham (IEEE, New York 2001), p. 326 (ISBN: 0-7803-5815-5).

${ }^{32}$ H. J. Schulz and M. Thiede, Phys. Rev. B 35, 18 (1987). 